\title{
Study on optimization of extraction technique of pericarp essential oil in Litsea Cubeba (Lour) Pers
}

\author{
Peng Huang ${ }^{1}$ - Zhanying Gu${ }^{1}$ (I) - Ling Yang ${ }^{1} \cdot$ Ruonan Yang ${ }^{1}$ - Yaxin $\mathrm{Ji}^{1} \cdot$ Qingyang Zeng ${ }^{1} \cdot$ Fangmeng Xiao $^{2}$. \\ Hanyue Chen ${ }^{2}$
}

Received: 2 June 2020 / Accepted: 9 September 2020 / Published online: 30 September 2020

(c) The Author(s) 2020

\begin{abstract}
Litsea cubeba is an important aromatic oil plant. Litsea cubeba pericarp essential oil has various physiological activities such as antibacterial activity, antioxidant capacity, etc., and is widely used. Its main ingredient is citral, which is the raw material for the synthesis of many precious spices. For the purpose of increasing yield, researchers have conducted many studies on the extraction of essential oil from pericarp of Litsea cubeba. But the extraction process still has room for optimization。In this study, Litsea cubeba fruits were subjected to an optimized method of hydrodistillation to increase the yield and biological activity of pericarp essential oils. Three-factor and three-level orthogonal experimental design was performed (fruit preservation time, distillation voltage and fruit microwave pretreatment time) to optimize the process. According to the results of orthogonal experiments, the highest yield of essential oil can be obtained after the fruit has been preserved for 9 days without microwave pretreatment and the distillation voltage is $220 \mathrm{~V}$. The extracted essential oils were analyzed by gas chromatography-mass spectrometry (GC-MS), which indicated that their main components were 2,6-Octadienal, 3,7-dimethyl-, (E)-, 2,6-Octadienal, 3,7-dimethyl-, (Z)-, 1-Heptanol and 1-Octanol. GC-MS results showed that the relative content of citral in the extracted essential oil was the highest after the fruit was preserved for nine days without microwave pretreatment and the distillation voltage was $150 \mathrm{~V}$. Changes in the process will not significantly affect the main component types of essential oils, but will significantly affect the relative content of the same components.
\end{abstract}

Keywords Litsea cubeba $\cdot$ Pericarp $\cdot$ Essential oil $\cdot$ Hydrodistillation $\cdot$ GC-MS

Zhanying Gu

guzhanying99@163.com

Peng Huang

979914967@qq.com

Ling Yang

2723857159@qq.com

Ruonan Yang

447402981@qq.com

Yaxin Ji

530162007@qq.com

Qingyang Zeng

275480458@qq.com

Fangmeng Xiao

xiaofangmeng11@163.com

Hanyue Chen

2097555901@qq.com

1 Forestry College, Central South University of Forestry and Technology, Changsha 410004, China

2 Bangor College, Central South University of Forestry and Technology, Changsha 410004, China

\section{Introduction}

Litsea cubeba (Lour.) Pers. is a deciduous shrub or dungarunga, belonging to the family Lauraceae and genus Litsea. There are about 250 species in the world, the main producing areas are in eastern Asia, Oceania and the Pacific Islands, China, India, Malaysia, Indonesia and other countries [1]. The stems and bark of L. cubeba are smooth with green or yellow-green colour; the leaves are alternate and simple and have an aromatic smell. The blooming stage is from February to March and the fruiting stage is from July to August. L. cubeba is a sunny tree species, mostly growing on sunny slopes, cutting sites, fire sites, thickets and sparse forests, with an altitude of about $300 \sim 1000 \mathrm{~m}$. L. cubeba is dioecism, anemophily and has the low requirement of site conditions, can grow very well in the slope of barren soil or the top of the hill [2].

The whole plant of L. cubeba contains oils, and the yields of oils in different organs are different [3]. The highest oil 
yield of all the organs is the fruit. The essential oils yield of fresh fruit is $3.0 \%$ to $6.0 \%$ [4]. L. cubeba pericarp essential oil is a light yellow translucent oily liquid with a smell similar to lemon oil. A number of studies [3, 5-9] have suggested that $L$. cubeba pericarp essential oil has a broad spectrum of antibacterial activity, and has inhibitory effects on a variety of common bacteria and fungi, such as Candida albicans, Escherichia coli, Aspergillus flavus, Penicillium, yeast, etc. Studies have suggested that $L$. cubeba pericarp essential oil has a strong antioxidant capacity $[5,10,11]$. L. cubeba pericarp essential oil has an antiasthmatic effect and the affective component is citral [12]. The antiallergic activity of L. cubeba pericarp essential oil has been demonstrated in animal experiments [13]. Yang [14] found that L. cubeba pericarp essential oil has the function of repelling insects in his study when the concentration is $10 \mathrm{~g} / \mathrm{kg}$, the killing rate of Sitophilus zeamais and Trogossitidae reaches 100\%. Several studies [15-17] have also found that L. cubeba pericarp essential oil has antithrombotic and antiarrhythmic effects. With so many functions, L. cubeba pericarp essential oil is widely used in many fields, such as the synthesis of highgrade spices, pharmaceutical applications, food additives and so on. The synthesis of high-grade spices is the main way of $L$. cubeba pericarp essential oil application, which is generally made into $85 \% \sim 97 \%$ citral, and then used in the synthesis of various spices [18]. In recent years, the world's perfume industry has developed rapidly. According to statistics from Leffingwell \& Associates [19], the world's perfume industry's yield value increased from the US $\$ 7.8$ billion in 1990 to the US $\$ 26.3$ billion in 2017. In particular, synthetic fragrances are found to be unsafe, and natural fragrances are becoming more and more optimistic for consumers, which has led to the continuous increase in the price of $L$. cubeba pericarp essential oil, which is now 300,000 to 400,000 yuan per ton [20].

So far, many methods have been used to extract $L$. cubeba pericarp essential oils, including hydrodistillation (HD) [21], solvent extraction (SE) [22], compression method [23], enzymatic assisted extraction (EAE) [24], supercritical fluid extraction (SFE) [25], and microwaveassisted extraction (MAE) [26]. Among all these methods, HD method, solvent extraction and compression method are traditional methods for extracting $L$. cubeba pericarp essential oil [27]. The disadvantages of these traditional methods are time-consuming, high operating temperature, degradation of target compounds, low yields and high energy consumption. Current research on enzymatic assisted extraction method of L. cubeba is rare, it only appeared in Xie's research [24], EAE method is a new method of extracting plant essential oil by using enzymehydrolysis reaction to destroy the structure of the cell wall of plant tissue so that the effective components in the tissue cell can be dissolved in the solvent [28]. The advantage of this method is that biological enzymes (e.g., cellulase, pectinase, etc.) can decompose plant tissue under mild conditions, which can save extraction time, improve yield and reduce the destruction of active components. The disadvantage is the high cost. Du et al. [29] optimized the extraction process of the essential oil of $L$. cubeba by the vacuum distillation technology combined with the response surface method under the ultrasonicassisted method. Under the optimal process conditions, the yield of essential oil was $6.94 \%$, and the content of essential oil citral It also reached $87.65 \%$.

but did not indicate the characteristics of the method. Supercritical fluid extraction is a relatively advanced and effective physical extraction method in the twenty-first century. The extraction of L. cubeba pericarp essential oil with this method has advantages that are unmatched by traditional methods such as convenient and fast operation. However, using this method requires expensive equipment and not suitable for large-scale production. In recent years, MAE method has emerged in the extraction of natural products with the advantages of simple equipment, low cost, saving reagents, shortening time, improving efficiency, and better extraction effect of volatile components such as volatile oils [30, 31]. Liu et al. [32] used MAE to extract L. cubeba pericarp essential oil, with an average yield of $8.38 \%$ and the highest yield of $8.6 \%, 2.46 \%$ higher than the hydrodistillation method, which is also the highest yield of L. cubeba essential oil reported at present. Qiu et al. [33] used the MAE method to extract the pericarp essential oil from $L$. cubeba in the research. The research results showed that MAE improved the yield by more than $50 \%$ compared with the traditional HD method.

The MAE method is environmentally friendly and safe, has high yield and low cost, and maybe put into largescale production. Hien et al. [34] studied the use of RSM to optimize microwave-assisted hydrodistillation (MAHD) to extract pomelo oil and found that hydrodistillation time, irradiation power and plant/liquid ratio are factors that affect the yield. Mollaei et al. [35] optimized the yield through the central composite design of the response surface methodology using three variable factors (hydrodistillation time, irradiation power and plant/liquid ratio) in their research.

So far, there are a few studies on the optimization of the extraction technique of $L$. cubeba pericarp essential oil by MAHD. In our research, MAE method was used as pretreatment, and the effects of fruit preservation time (FPT), distillation voltage (DV), and microwave pretreatment time (MP) on the extraction of $L$. cubeba by HD were explored. The aim of our research is to analyze the yield and components of the pericarp essential oils to study the differences from traditional HD, and also to determine the optimal combination of levels of three factors: FPT, DV and MP, to optimize the HD process of extracting the L. cubeba pericarp 
essential oil, and provide a reference for subsequent research and production.

\section{Materials and methods}

\section{Plant material}

Experiment seedlings were transplanted from the nursery of Central South University of Forestry and Technology, planted in 2010, the planting density is $4 \mathrm{~m} * 3 \mathrm{~m}$; Fertilized $280 \mathrm{~g}$ compound fertilizer (46.4\% urea, $18 \%$ superphosphate, $100 \%$ potassium carbonate, the ratio is $3: 2: 2$ ) per plant; weeding twice a year.

All the L. cubeba fruit used in the research was collected at the end of August when the outer skin of the fruit is cyan, lustrous and wrinkle-free, and when the outer skin can be peeled off with fingers. And the fruits were preserved in the refrigerator, the temperature is $4{ }^{\circ} \mathrm{C}$.

\section{Hydrodistillation}

All experiments used HD method to extract the pericarp essential oil of the L. cubeba and the distillation process was heated with a $1000 \mathrm{~mL}$ DZTW temperature-regulating heating mantle (produced by Beijing Yongguangming Medical Instrument Co., Ltd.). Microwave pretreatment is performed with domestic microwave oven (P70D20N1PG5(W0), Galanz, China, 20L), and the full output power is $700 \mathrm{~W}$. Briefly, fruits were placed in a $1000 \mathrm{~mL}$ round bottom flask equipped with a Clevenger apparatus, and distilled with $1000 \mathrm{~mL}$ of pure water for $2 \mathrm{~h}$. The pericarp essential oil yield (\%) was calculated according to the below equation:

Yield $(\%)=\frac{\text { The amount of the pericarp essential oil }(\mathrm{g})}{\text { The amount of fruit }(\mathrm{g})} \times 100$

\section{Single-factor experiments}

In our study, we set up three single-factor (FPT, DV and MP) with five-level experiments under the same conditions (Plant/liquid ratio 1:10; distillation for $2 \mathrm{~h}$ ). When conducting single-factor experiments, the other factors are controlled as FPT is 2 days, DV is $150 \mathrm{~V}$ and no MP and the levels were shown in Table 1.

\section{Orthogonal experimental design}

In our study, a three-factor (FPT, DV and MP) with the three-level test was conducted based on the results of singlefactor experiments (Choose the three levels with the highest acquisition rate). Their levels were set to 3 days, 6 days and
Table 1 Single-factor five-level experiment design and three-factor three-level experiment design

\begin{tabular}{|c|c|c|c|c|}
\hline \multicolumn{2}{|l|}{ Factors } & \multirow{2}{*}{$\frac{\text { FPT (d) }}{1}$} & \multirow{2}{*}{$\frac{\mathrm{DV}(\mathrm{V})}{250}$} & \multirow{2}{*}{$\frac{\mathrm{MP}(\mathrm{s}}{0}$} \\
\hline Levels & Symbols & & & \\
\hline & 1 & $3^{*}$ & $220 *$ & $10 *$ \\
\hline & 2 & $6^{*}$ & $150 *$ & $30 *$ \\
\hline & 3 & $9 *$ & $100 *$ & $60 *$ \\
\hline & & 13 & 50 & 90 \\
\hline
\end{tabular}

Symbols mean the serial number of levels in three-factor three-level experiment design the difference is significant $(\mathrm{P}<0.02)$

*Is the levels of the three-factor three-level experiment

9 days; $100 \mathrm{~V}, 150 \mathrm{~V}$ and $220 \mathrm{~V} ; 0 \mathrm{~s}, 10 \mathrm{~s}$ and $30 \mathrm{~s}$ (Table 1). The orthogonal experimental design is shown in Table 3.

\section{Gas chromatography-mass spectroscopy (GC-MS)}

Take $0.05 \mathrm{~mL}$ of the pericarp essential oil, makeup to a $10 \mathrm{~mL}$ volumetric flask with anhydrous hexanol, pass through a $0.22 \mu \mathrm{m}$ filter membrane, and reserve for GC-MS. Three replicates were determined for each sample.

Gas chromatographic conditions: Chromatographic column HP-5MS quartz capillary column (30 $\mathrm{m} \times 0.25 \mathrm{~mm} \times 0.25 \mu \mathrm{m})$; Programmatic heating: Initial temperature of the column is $50^{\circ} \mathrm{C}$. After holding for $2 \mathrm{~min}$, heat up to $125^{\circ} \mathrm{C}$ at a rate of $3{ }^{\circ} \mathrm{C} / \mathrm{min}$ and keep $1 \mathrm{~min}$, then heat up to $250{ }^{\circ} \mathrm{C}$ at $15^{\circ} \mathrm{C} / \mathrm{min}$ for $5 \mathrm{~min}$; the carrier gas is high-purity helium (99.999\%); pre-column pressure, flow rate, injection volume, scan time, injector temperature, and split ratio are $50 \mathrm{kPa}, 1 \mathrm{~mL} / \mathrm{min}, 1 \mu \mathrm{L}, 4 \mathrm{~min}, 220^{\circ} \mathrm{C}, 1: 40$, respectively.

Mass spectrometry conditions: Ion source is EI source; ionization voltage is $70 \mathrm{eV}$; mass scanning range: $30-550$ amu; quadrupole temperature is $150^{\circ} \mathrm{C}$; ion source temperature is $230{ }^{\circ} \mathrm{C}$; interface temperature is $260^{\circ} \mathrm{C}$.

\section{Data analysis}

The software used for data analysis was IBM SPSS Statistic 21. Statistical analysis was performed on the data obtained from three single factor experiments by one-way analysis of variance (ANOVA), and the significant difference between the mean values was determined by least significant difference (LSD) test $(\mathrm{P}<0.05)$. The Spearman's rank correlation coefficient was used to analyze the correlation between the factor and yield of $L$. cubeba pericarp essential oil extraction by $\mathrm{HD}(\mathrm{P}<0.05$ is significant correlation $)$, and a linear regression equation was listed. 


\section{Results and discussion}

According to previous studies [36-38], microwave power, hydrodistillation time, and plant/liquid ratios may affect the yield of microwave assisted hydrodistillation on a variety of plant essential oil, including L. cubeba. Most of these studies carried microwave assistant during hydrodistillation. Different from previous studies, this research innovatively attempts to use microwave as a pretreatment on L. cubeba fruits before extracted by hydrodistillation; and for the first time, the effect of factors on the steam distillation extraction process of $L$. cubeba pericarp essential oil was studied.

\section{Effect of three factors on the yield of $L$. cubeba pericarp essential oil extracted by HD methond}

In a single-factor experiment with FPT as the factor, when the DV is maintained at $150 \mathrm{~V}$ and no MP except that the difference between the 3-day level and the 6-day level is not significant, there are significant differences between the other levels, the experimental results (Fig. 1 and Table 2) are as follows: When the FPT is 1 days, the yield of the pericarp
Fig. 1 Effect of FPT, DV and MP on the yield of L. cubeba pericarp essential oil extracted by HD method. Data shown are mean of $\pm \operatorname{SD}(n=3)$. Error bar: $95 \% \mathrm{Cl} .{ }^{\mathrm{a}-\mathrm{e}}$ Represents the difference between the data, the same letter means the difference is not significant, and the different letters mean the difference is significant $(\mathrm{P}<0.02)$
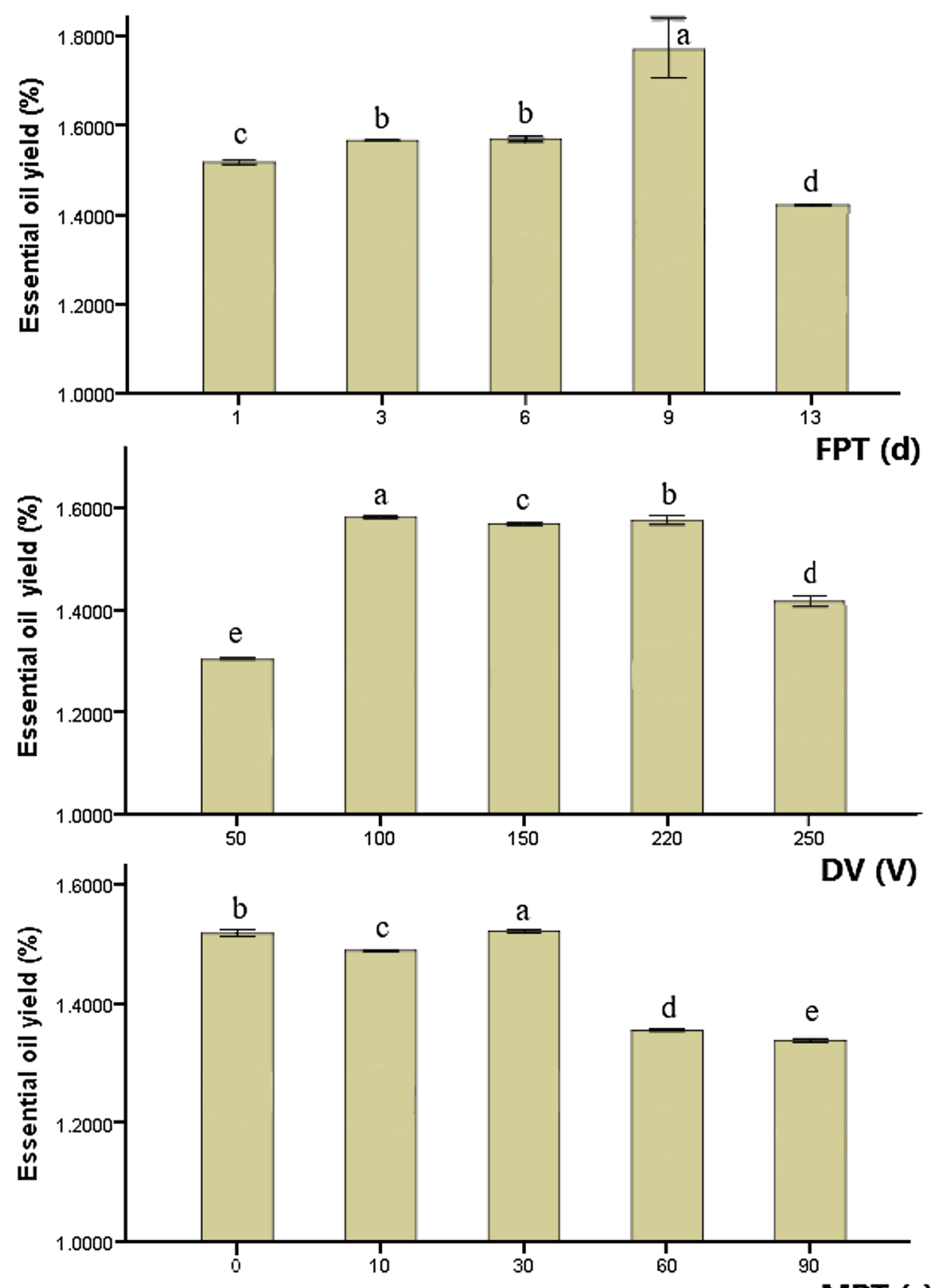
Table 2 Result of the yield of L. cubeba pericarp essential oil in three single factor experiments (FPT, DV, and MP)

\begin{tabular}{llllll}
\hline FPT(d) & Yield (\%) & DV(V) & Yield (\%) & MP(s) & Yield (\%) \\
\hline 1 & $1.5181^{\mathrm{c}}$ & 50 & $1.3029^{\mathrm{e}}$ & 0 & $1.5181^{\mathrm{b}}$ \\
3 & $1.5667^{\mathrm{b}}$ & 100 & $1.5819^{\mathrm{a}}$ & 10 & $1.4892^{\mathrm{c}}$ \\
6 & $1.5702^{\mathrm{b}}$ & 150 & $1.5687^{\mathrm{c}}$ & 30 & $1.5221^{\mathrm{a}}$ \\
9 & $1.7705^{\mathrm{a}}$ & 220 & $1.5760^{\mathrm{b}}$ & 60 & $1.3547^{\mathrm{d}}$ \\
13 & $1.4219^{\mathrm{d}}$ & 250 & $1.4165^{\mathrm{d}}$ & 90 & $1.3380^{\mathrm{e}}$ \\
\hline
\end{tabular}

${ }^{a-e}$ Represent the differences between the data. the same letter means the difference is not significant, and the different letters mean the difference is significant $(\mathrm{P}<0.02)$

essential oil is $1.5181 \%$. As the FPT was extended to 3 days, the yield increased significantly, reaching $1.5667 \%$, which was $3.2 \%$ higher than the 1 days level. When the FPT was further extended to $6 \mathrm{~d}$, it is shown that the yield had a slight increase, which was not significant. When the reservation time was 9 days, the yield increased significantly, reaching $1.7705 \%$, which was the highest of the five levels and $16.6 \%$ higher than the 1 days level. When the FPT exceeded 9 days, the yield began to decrease significantly. At 13 days, the yield was $1.4219 \%$, which was much lower than the 1 days level. From the results of the single factor experiment of FPT (Fig. 1), with the increase of the FPT, the yield of L. cubeba pericarp essential oil increased, and it reached the highest at 9 days level, and then began to decline. The result was not only be affected by FPT but also by preservation conditions. From the current experimental results, the FPT is within the range of 1-9 days. Increasing the FPT can increase the yield of $L$. cubeba pericarp essential oil. This is contrary to the general law. Under normal circumstances, the yield of plant essential oils will decrease as the FPT increases. For example, in the study of $\mathrm{Wu}$ and $\mathrm{Xu}$ [39], regardless of the storage conditions, the yield of L. cubeba essential oil decreases with the FPT. At present, the research on the effect of FPT on the essential oil of $L$. cubeba pericarp has focused on the effect on the components $[26,40]$. The effect on the yield has not been reported. The reason for this result is currently unknown, and further studies are needed. However, referring to the research of Chen [41], it can be guessed that this change may be related to the maturity of the fruit; it is possible that the L. cubeba in this study has not yet fully matured; during the nine-day preservation process, the fruit continues to mature. Therefore, the yield of fruit essential oil increases with the increase of MPT. Chen [41] studied the effect of fruit maturity on the extraction yield and chemical composition of $L$. cubeba essential oils. He found that the yield of immature fruit essential oil was $2.75 \%$, the yield of mature fruit essential oil was $2.79 \%$, and the essential oil yield of overripe fruit was $2.79 \%$. The dynamic change of essential oil yield with fruit maturity in Chen's study is similar to the dynamic change of essential oil yield with FPT in this study, so we can further guess that the decrease in yield when FPT increases from 9 to 13 days is caused by overripe of fruits. There is a critical time around 9 days when the fruit is fully mature and the yield of essential oil reaches the highest value. This requires more experiments to verify.

In the single-factor experiment with DV as the factor, under the condition that the FPT is kept at 2 days and no MP there was a significant difference between the five levels, the experimental results (Fig. 1 and Table 2) are as follows: The yield of distillation at a voltage of $50 \mathrm{~V}$ is $1.3029 \%$, which is the lowest of the five levels. When the voltage increased to $100 \mathrm{~V}$, the yield increased greatly, reaching $1.5819 \%$, which was the highest of the five levels, which increased by $21.4 \%$ compared with the $50 \mathrm{~V}$ level. As the voltage continues to increase, the yield fluctuates. When the voltage rises to $150 \mathrm{~V}$, the yield drops to $1.5686 \%$, a significant decrease. As the voltage continues to increase, the yield fluctuates. When the voltage rises to $150 \mathrm{~V}$, the yield drops significantly to $1.5686 \%$. When the voltage increased to $220 \mathrm{~V}$, the yield increased significantly. In the process of increasing the voltage from 220 to $250 \mathrm{~V}$, the yield decreased significantly, by $10.1 \%$ compared with the $220 \mathrm{~V}$ level. From the single-factor experiment results (Fig. 1), the DV did have a significant effect on the yield of $L$. cubeba pericarp essential oil. With the increase of DV, yield first increases sharply from 50 to $100 \mathrm{~V}$, then stopped increasing, and then fluctuated from 100 to $150 \mathrm{~V}$ to $220 \mathrm{~V}$, and finally decreased sharply. In this study, the instrument used for HD is a temperature-regulating heating mantle. The change in voltage affects the temperature during distillation, and voltage and temperature are positively correlated. According to research records, the higher the voltage, the higher the distillation temperature, and the earlier the oil released during distillation. Since all experimental distillation times are $2 \mathrm{~h}$, the earlier the oil is released, the longer the oil extracted would last, which directly increases yield. Moreover, according to a mechanism mentioned by Zhang et al. [42] and Soran et al. [43]: High temperature reduced the viscosity of water, which helped heat to penetrate cells faster. In this case, some temperature-sensitive metabolites may break down, which in turn affects the yield and quality of the pericarp essential oils. This can explain why as the voltage rises, the yield rises sharply, then no longer rises and fluctuates, and finally drops sharply. From the current experimental results, the DV is in the range of 50-220 V. Increasing the DV can increase the yield of L. cubeba pericarp essential oil.

In the single factor experiment with the MP as the factor, keeping the FPT at 2 days and the DV at $150 \mathrm{~V}$, there was a significant difference between the five levels, the experimental results (Fig. 1 and Table 2) are as follows: Yield of L. cubeba pericarp essential oil without MP was $1.5181 \%$; the yield of fruit after $10 \mathrm{~s}$ MP was reduced to $1.4892 \%$, which was significantly reduced by $1.9 \%$ compared with 
that without MP. After a longer MP, it was shown that the yield increased significantly between 10 and $30 \mathrm{~s}$ of MP, increasing to $1.5221 \%$. With the further extension of the MP, the yield has greatly reduced, after MP for $60 \mathrm{~s}$, it has decreased to $1.3547 \%$, which is $11.0 \%$ compared with the previous level. After $90 \mathrm{~s}$ of MP, it has been significantly reduced again to $1.3380 \%$, Which is the lowest of the five levels. From the results of the single factor experiment of the MP (Fig. 1), the MP did have a significant effect on the yield of $L$. cubeba pericarp essential oil. Compared with no MP, after $10 \mathrm{~s}$ of pretreatment, the yield of the L. cubeba pericarp essential oil reduced; when the time was extended to $30 \mathrm{~s}$, the yield increased, but as the time further increased, the yield began to continue to decline. Mollaei et al. [35] found that the temperature increase caused by microwaveinduced molecular motion may reduce the yield of the pericarp essential oils: the electromagnetic waves of microwaves heat water in plant cells and cause plant cell walls to rupture, which can explain the reason why there was a fall between 0 and $10 \mathrm{~s}$. As pretreatment time increased, the destruction of plant cell walls intensified, more and more essential oils escape from the cells, which increases the yield in a short time (10-30 s) and the yield reached the highest. When the MP continues to increase, the dissolution rate of impurities gradually increases due to the excessive rupture of the cell wall, and the yield of essential oils decreases, which is consistent with Wu's view [44]. Besides, MP increased the volatility of the pericarp essential oils in vegetable oils or some temperature-sensitive metabolites may decompose, which affects the content and quality of the pericarp essential oils. Due to the mechanism above, the MP is not stable for the increase of yield, and after too long pretreatment time, it shows that the yield is greatly weakened. From the current results, MP has small improvement in improving the yield of $L$. cubeba pericarp essential oil extracted through HD; the MP should be accurately controlled at about $30 \mathrm{~s}$, otherwise, the change of time will reduce the yield.

\section{Multi-factor experiment}

\section{The extracted pericarp essential oil contents}

In order to optimize the extraction process of $L$. cubeba pericarp essential oil, an orthogonal experiment of $\mathrm{L}_{9}\left(3^{3}\right)$ was carried based on the results of single-factor experiments. The experimental results are shown in Table 3. The results of the nine experiments vary greatly. The smallest is the No. 3 experiment, only $1.3292 \%$, which is only $68.1 \%$ of the average yield of the nine experiments; the largest is the No. 7 experiment, which reached $2.4479 \%$, it is $25.4 \%$ higher than the average yield and is near twice the result of the No. 3 experiment. It shows that the optimization potential of HD extraction process of L. cubeba pericarp essential oil is huge.
From Table 3, it is shown that the maximum $\mathrm{k}$ values of the three factors (FPT, DV and MP) are k3, k1, and k1, respectively, the levels they represent are 9 days, $220 \mathrm{~V}$ and $0 \mathrm{~s}$. Therefore, the best HD extraction process for L. cubeba pericarp essential oil was: FPT of 9 days, DV of $220 \mathrm{~V}$, and no MP. The largest of the " $r$ " values of the three factors is the FPT, which indicates that the FPT is the most important factor of the HD extraction process of L. cubeba pericarp essential oil among the three factors. Followed by the factor of the MP, and the last was DV.

\section{Components of extracted pericarp essential oil}

GC-MS analysis was used to detect the composition of $L$. cubeba pericarp essential oil from orthogonal experiments to study the effects of different extraction processes on the components of the pericarp essential oil. After analysis of the pericarp essential oil samples of each experiment, it was found that each sample contained 15-20 components, and only the components with the relative content ranked in the top 4 and the relative content greater than $8 \%$ were mentioned (Fig. 2). The relative contents of the other components were all below 3\%. The results are shown in Table 4 . The main types of components were not significantly different among samples. The three components with the highest relative content were 2,6-Octadienal, 3,7-dimethyl-, (E)-, 2,6-Octadienal, 3, 7-dimethyl-, (Z)-and 1-Heptanol. The only difference is that Octel chloroformate $(9.157 \%)$ has the fourth-highest relative content in experiments No. 1 and 1-Octanol has the fourth-highest relative content in experiments No. 2-9. The different extraction process of $L$. cubeba pericarp essential oil has significant effects on the relative content of each component. For component 2,6-Octadienal, 3,7-dimethyl-, (E)-, the difference between the results of each experiment is significant, the average of all experimental results is $30.986 \%$, and the highest relative content is experiment No. $8(33.049 \%)$, the lowest is experiment No. $6(28.013 \%)$, the difference is $5.036 \%$. For the components 2,6-Octadienal, 3,7-dimethyl-, (Z)-, the difference between No. 4 and No. 5 is not significant, and there is no difference between No. 7 and No. 9, the differences between the results of other experiments are all significantly, the average of all experimental results was $25.696 \%$, the highest relative content was experiment No. 8 (27.447\%), and the lowest was experiment No. 2 (23.953\%), a difference of $3.494 \%$. For component 1-Heptanol, the difference between the results of each experiment is significant, the average of all experimental results is $11.710 \%$, the highest relative content is experiment No. 5 (12.847\%), and the lowest is experiment No. $9(10.540 \%)$, the difference is $2.307 \%$. For component 1-Octanol, only the differences between the experimental results of No. 7 and No. 8 were not significant, and the differences between each of the other experimental results 
Fig. 2 The total ion current of L. cubeba pericarp essential oil extracted by HD method in the orthogonal experiment

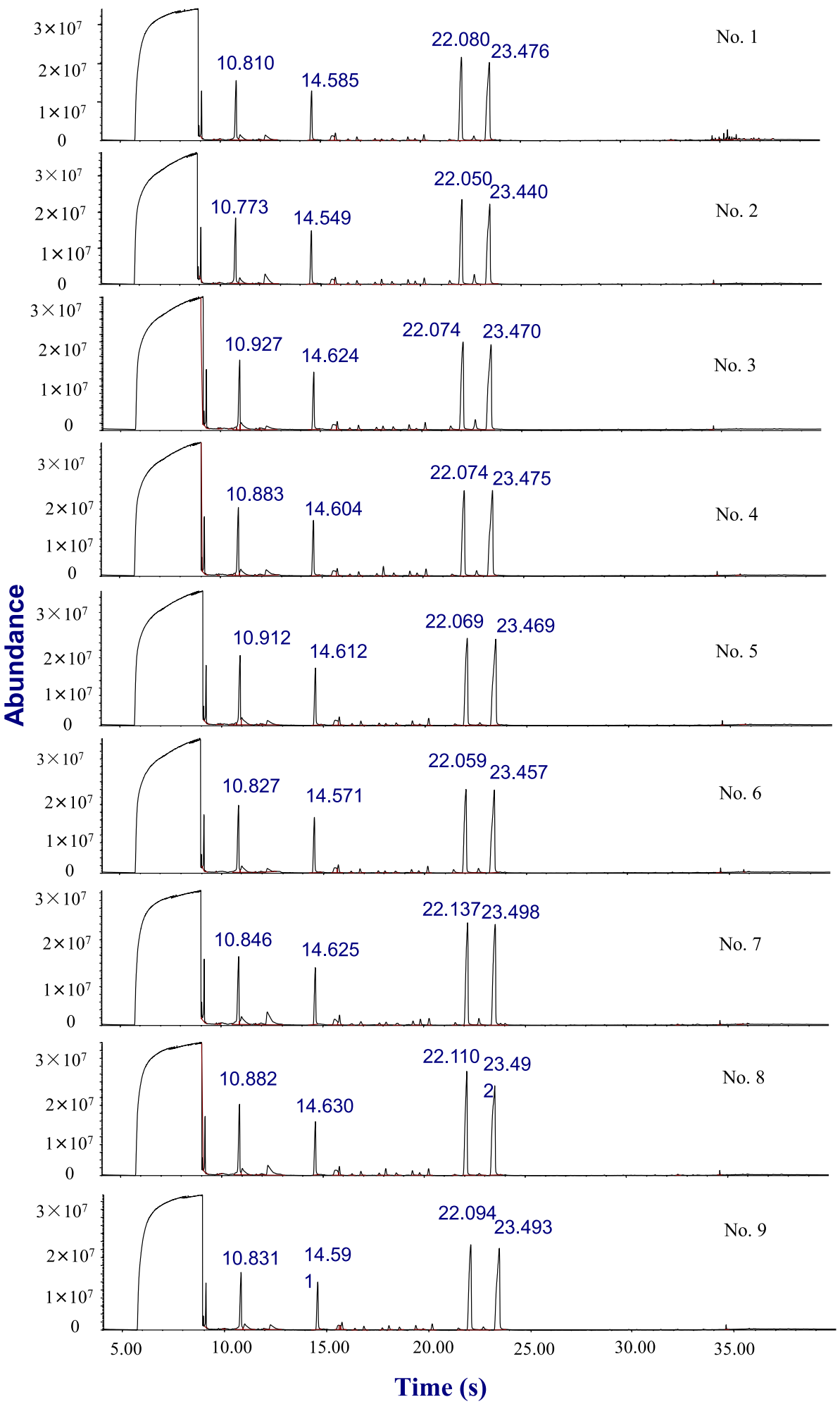

were significant. The average of all experimental results was $9.191 \%$, and the highest relative content was experiment No. $5(10.078 \%)$, the lowest is experiment No. 9 (8.653\%), the difference is $1.425 \%$. Factors influencing the component of L. cubeba pericarp essential oil extracted through HD.
From the results of GC-MS analysis, it can be known that the main compositions of the L. cubeba pericarp essential oil extracted from the nine pericarp essential oil extraction processes are basically the same, and the four components with the highest relative content are 2,6 -Octadienal, 
Table 3 Results of pericarp essential oil yield of the orthogonal experiment

\begin{tabular}{lllll}
\hline No & Factors & & & $\begin{array}{l}\text { Yield of pericarp } \\
\text { essential oil (\%) }\end{array}$ \\
\cline { 2 - 4 } & FPT (d) & DV $(\mathrm{V})$ & MP (s) & \\
\hline 1 & 1 & 1 & 1 & 1.9336 \\
2 & 1 & 2 & 2 & 1.5667 \\
3 & 1 & 3 & 3 & 1.3292 \\
4 & 2 & 1 & 2 & 1.8735 \\
5 & 2 & 2 & 3 & 1.7236 \\
6 & 2 & 3 & 1 & 2.0951 \\
7 & 3 & 1 & 3 & 2.4479 \\
8 & 3 & 2 & 2 & 2.4234 \\
9 & 3 & 3 & 2 & 2.1808 \\
$\mathrm{k}_{1}$ & 1.6098 & 2.0850 & 2.1507 & \\
$\mathrm{k}_{2}$ & 1.8974 & 1.9046 & 1.8737 & \\
$\mathrm{k}_{3}$ & 2.3507 & 1.8684 & 1.8336 & \\
$\mathrm{r}$ & 0.7409 & 0.2166 & 0.3171 & \\
\hline
\end{tabular}

The numbers " $1,2,3$ " in the table are the serial number of levels (see Table 1 for the specific values). " $\mathrm{k}$ " is the mean of the results of all the same level numbers in each factor, and " $r$ " is the difference between the largest " $\mathrm{k}$ " value and the smallest " $\mathrm{k}$ " value within the same factor

Table 4 The main components and their relative content of the $L$. cubeba pericarp essential oil from the orthogonal experiment

\begin{tabular}{lllll}
\hline No & \multicolumn{4}{l}{ Relative content $(\%)$} \\
\cline { 2 - 5 } & $\begin{array}{l}\text { 2,6-Octadienal, } \\
\text { 3,7-dimethyl-, } \\
\text { (E)- }\end{array}$ & $\begin{array}{l}\text { 2,6-Octadienal, } \\
\text { 3,7-dimethyl-, } \\
(\mathrm{Z})-\end{array}$ & 1-Heptanol & 1-Octanol \\
\hline 1 & $30.279^{\mathrm{f}}$ & $25.340^{\mathrm{d}}$ & $11.863^{\mathrm{d}}$ & - \\
2 & $29.462^{\mathrm{h}}$ & $23.953^{\mathrm{g}}$ & $12.153^{\mathrm{c}}$ & $9.316^{\mathrm{c}}$ \\
3 & $30.211^{\mathrm{g}}$ & $24.757^{\mathrm{e}}$ & $11.258^{\mathrm{g}}$ & $9.179^{\mathrm{d}}$ \\
4 & $31.592^{\mathrm{d}}$ & $25.776^{\mathrm{c}}$ & $11.733^{\mathrm{e}}$ & $9.457^{\mathrm{b}}$ \\
5 & $31.372^{\mathrm{e}}$ & $25.747^{\mathrm{c}}$ & $12.847^{\mathrm{a}}$ & $10.078^{\mathrm{a}}$ \\
6 & $28.013^{\mathrm{i}}$ & $24.335^{\mathrm{f}}$ & $11.484^{\mathrm{f}}$ & $8.653^{\mathrm{g}}$ \\
7 & $32.241^{\mathrm{c}}$ & $26.966^{\mathrm{b}}$ & $12.337^{\mathrm{b}}$ & $9.040^{\mathrm{e}}$ \\
8 & $33.049^{\mathrm{a}}$ & $27.447^{\mathrm{a}}$ & $11.177^{\mathrm{h}}$ & $9.054^{\mathrm{e}}$ \\
9 & $32.654^{\mathrm{b}}$ & $26.944^{\mathrm{b}}$ & $10.540^{\mathrm{i}}$ & $8.752^{\mathrm{f}}$ \\
\hline
\end{tabular}

${ }^{a-i}$ Represent the differences between the data. the same letter means the difference is not significant, and the different letters mean the difference is significant $(\mathrm{P}<0.02)$

3,7-dimethyl-, (E)-, 2,6-Octadienal, 3,7-dimethyl-, (Z)-, 1-Heptanol and 1-Octanol, which means that these nine processes will not affect the type of the main compounds of the L. cubeba pericarp essential oil significantly. Among them, the citral (2, 6-octadienal, 3,7-dimethyl-, (E)- and 2, 6-octadienal, 3,7-dimethyl-, (Z)-) occupied the majority, which was consistent with previous studies [40,45, 46], but the situation that 1-heptanol and 1-octanol became the main components was not found in previous studies. It can also be known from the results that the effects of different processes on the relative content of the same component are significantly different. It can be clearly seen that the content of citral in the pericarp essential oil extracted in the experiments No. 7-9 is greater than that in other experiments. According to the results, among the nine experiments, the relative content of citral in the pericarp essential oil extracted in experiment No. 8 was the highest, so the level combine of FPT of 9 days, the DV of $150 \mathrm{~V}$, no microwave pre-treatment is the best process to produce $L$. cubeba pericarp essential oil with high citral content among the 9 processes. According to Tables 1 and 3, it can be seen that the experimental materials of experiments No. 7-9 are L. cubeba fruit preserved for 9 days, which indicates that preservation in the refrigerator for 9 days can increase the citral relative content of the L. cubeba pericarp essential oil. The factor of FPT has the greatest influence on the component of L. cubeba pericarp essential oil. But this is inconsistent with the results of previous studies: Han [37] and Fu [26] both found that with the increase of FPT, the citral content in L. cubeba essential oil decreased. The difference with the results of previous studies may be caused by two reasons: one is that the FPT is not long enough, and short-term preservation will not affect the composition of essential oils. In Han's research, the fruits were preserved until they shriveled; in Fu's research, the fruits were preserved for six months, and their fruits were preserved for too long. The second is that the L. cubeba fruit in this study is not yet fully mature, and gradually approaches maturity during preservation. Chen [41] studied the effect of L. cubeba fruit maturity on the extraction yield and chemical composition of essential oils. $\mathrm{He}$ found that the essential oil citral content extracted from immature fruits was $68 \%$, and the essential oil citral content extracted from mature fruits was $78 \%$. The citral content of the essential oil extracted from overripe fruits is $74 \%$. This may explain why the essential oil citral content increased as the FPT increased in this study. Therefore, proper extension of FPT of $L$. cubeba fruit can increase the citral content of the essential oil, but not too much, otherwise the quality of the essential oil will decline. More research needs to be done to explore how long L. cubeba fuirt can be preserved without reducing the quality of its essential oils and the exact time of MPT that can obtain the highest quality essential oil.

\section{Correlation analysis between yield and three factors in single-factor experiments}

After correlation analysis using Spearman's rank correlation coefficient, the correlation between yield and three factors (FPT, DV, and MP) was learned. As Table 5 shows, the correlation coefficient between FPT and yield is -0.016 , and the significant value is 0.954 . This shows that the relationship between the two is negative, and the correlation is very 
Table 5 Result of Spearman's rank correlation analysis between factors and the yield of $L$. cubeba pericarp essential oil extraction by HD method

\begin{tabular}{lllll}
\hline Factors & & FPT & DV & MP \\
\hline Yield & Correlation coefficient & -0.016 & 0.098 & $-0.687^{* *}$ \\
& Sig. (2-tailed) & 0.954 & 0.728 & 0.005 \\
& Number & 15 & 15 & 15 \\
\hline
\end{tabular}

**Means the correlation is significant at the 0.01 level (2-tailed)

small, and the correlation is very insignificant. The correlation coefficient between DV and yield is 0.098, and the significant value is 0.728 . This shows that the relationship between the two is a positive correlation, and the correlation is small and not significant. The correlation between MP and yield is -0.687 , with a significant value of 0.005 . This shows that the relationship between the two is a negative correlation, the correlation is large and extremely significant. The linear regression equation calculated by IBM SPSS Statistic 21 software is: $y=1.529-0.02 x$.

\section{Improved processing technology}

Based on the results of three single-factor experiments, three best levels of yield of $L$. cubeba pericarp essential oil for each factor was selected to perform an orthogonal experiment, and then predicted the optimal level combination for yield to optimized L. cubeba pericarp essential oil HD extraction process. From the results of orthogonal experiments (Table 3), the fruit yield time, DV, and microwave pre-treatment time were 9 days, $220 \mathrm{~V}$, and $0 \mathrm{~s}$, respectively, the " $k$ " values are highest and the yield reaches the maximum. From the results of GC-MS analysis (Table 4), the fruit yield time, DV, and microwave pre-treatment time were 9 days, $150 \mathrm{~V}$, and $0 \mathrm{~s}$, respectively, the citral content of L. cubeba pericarp essential oil reaches the maximum. In addition, the process has room for improvement. The level setting of the two factors of FPT and DV can also be optimized to explore a better L. cubeba pericarp essential oil HD extraction process.

\section{Conclusion}

We studied the effects of FPT, DV and fruit MP on extracting essential oil of $L$. cubeba by HD method, optimized the process, and analyzed the differences of essential oil components obtained by different processes. Among the three factors, the FPT and the DV within a certain range (1 days -9 days; 50-220 V) have a positive effect on the yield of the pericarp essential oil, and the MP of fruit has a negative effect on the yield of the pericarp essential oil; The duration of fruit placement has the greatest effect on increasing yield, followed by the DV. Then, under the influence of these three factors, the process of HD method to extract the essential oil of $L$. cubeba pericarp has the highest yield: the fruit is preserved for 9 days, the DV is $220 \mathrm{~V}$, and no MP. The extraction condition with the highest content of citral is 9 days preserved, $150 \mathrm{~V} \mathrm{DV}$ is, and no MP. Therefore, the former process should be used for mass production of essential oil of $L$. cubeba pericarp, and the latter should be used for the production of essential oil with high citral content. In addition, changes in the process will not significantly affect the main component types of essential oils, but will significantly affect the relative content of the same components. Microwave pretreatment can increase the yield of essential oil from $L$. cubeba pericarp, but too long a pretreatment time will reduce the yield. In addition, short-term preservation of L. cubeba fruit can increase the yield of essential oil in the pericarp and the content of citral, but the long-term preservation will reduce the yield and citral content. It is worthy of further research on how to preserve L. cubeba and how long the preservation can increase yield and quality.

Acknowledgements This research was funded by the National Key R\&D Program of China, Grant Number 2018YFD1000605.

Author contributions Conceptualization: ZG; Methodology: ZG and LY; Validation: ZG; Formal Analysis: PH; Investigation: ZG, LY, RY, YJ, QZ, FX and HC; Resources: ZG; Data Curation: PH; WritingOriginal Draft Preparation: PH; Writing-Review \& Editing: ZG; Supervision: ZG; Project Administration: ZG; Funding Acquisition: ZG.

Data availability The raw/processed data cannot be shared as the data also forms part of an ongoing study.

\section{Compliance with ethical standards}

Conflict of interest The authors declare that they have no conflict of interests.

Informed consent Written informed consent for publication was obtained from all participants.

Open Access This article is licensed under a Creative Commons Attribution 4.0 International License, which permits use, sharing, adaptation, distribution and reproduction in any medium or format, as long as you give appropriate credit to the original author(s) and the source, provide a link to the Creative Commons licence, and indicate if changes were made. The images or other third party material in this article are included in the article's Creative Commons licence, unless indicated otherwise in a credit line to the material. If material is not included in the article's Creative Commons licence and your intended use is not permitted by statutory regulation or exceeds the permitted use, you will need to obtain permission directly from the copyright holder. To view a copy of this licence, visit http://creativecommons.org/licenses/by/4.0/. 


\section{References}

1. X.J. Pan, W.J. Chen, H.B. Hou, Current processing and development of Litsea cubeba. Econ. For. Res. 21(1), 79-80 (2003). https ://doi.org/10.3969/j.issn.1003-8981.2003.01.029

2. H.J. Xue, Y.H. Xiao, J.M. He, Characteristics and comprehensive utilization of Litsea cubeba (Lour) pers. J. Anhui Agric. Sci 38(19), 10057-10058 (2010). https://doi.org/10.13989/j.c nki.0517-6611.2010.19.094

3. F.S. Wang, D.P. Yang, S.X. Ren, H.D. Zhang, R.W. Li, Chemical composition of essential oil from leaves of Litsea cubeba and its antifungal activities. J. Chin. Med. Mater. (1999). https://doi. org/10.13863/j.issn1001-4454.1999.08.013

4. L.F. Zhu, B.Y. Lu, B.L. Li, Y.J. Li, Y.R. Lin, L.Z. Jia, Lauraceae, in Aromatic plants and their chemical composition, ed. by C.Z. Fu (Hainan Publishing House, Haikou, 1993), pp. 78-113

5. R.Y. Gu, Y.Y. Liu, Study on the anti-oxidation and bacteriostasis of Litsea cubebaextraction oil. Food Sci. 27(1), 86-89 (2006). https://doi.org/10.1016/S1872-2040(06)60045-5

6. B.L. Yu, H.B. Luo, J. Zhou, J.N. Zhang, Study on the active ingredient of antibiotic activities of Litsea cubeba oil on moulds and the effect on aflatoxin production. J. Sichuan Inst. Light Ind. Chem. Technol. 15(1), 32-36 (2002). https://doi.org/10.3969/j. issn.1673-1549.2002.01.008

7. L. Wan, J.S. Zhu, Z.F. Li, F. Li, Effect of Litsea cubeba oil on disseminated candidiasis of mice. Chin. J. Mycol. 4(1), 211-214 (2006). https://doi.org/10.3969/j.issn.1673-3827.2006.04.005

8. Z.D. Xia, J.X. Yang, P.T. Li, Study on antifungal mechanism of Litsea cubeba oil in candida albicans. Bull. Hunan. Med. Univ. 20(2), 107-108 (1995)

9. M. Luo, L.K. Jiang, Z.J. Wu, Preliminary study on citral impaires the Aspergillus flavus membrane. Acta Microbiol. Sin. 41(6), 723730 (2001). https://doi.org/10.3321/j.issn:0001-6209.2001.06.012

10. C. Cheng, Study on the antioxidation of Litsea cubeba oil. Food. Res. Dev. 26(4), 155-158 (2005). https://doi.org/10.3969/j. issn.1005-6521.2005.04.058

11. B.L. Yu, Antioxidative activity of Litsea cubeba oil and its residue extractives. Chem. Ind. For. Prod. 18(2), 21-25 (1998)

12. X.C. Wu, Z.D. Zhang, S.Q. Pan, The pharmacological study of Litsea cubeba oil in Hunan province. China J. Chin. Mater. Med. 11(1), 53 (1986)

13. B.C. Qian, W.G. Gong, Y. Chen, Y.Q. Zhang, H.J. Xu, L.X. Zhang, Pharmacological studies on anti-asthmatic and anti-anaphylactic activities of the essential oil of Litsea cubeba (Lour) pers. Acta Pharm. Sin. 15(10), 584-589 (1980)

14. D.N. Yang, Using plants to control stored grain pests. Rural Econ. Technol. 10(8), 35 (1999)

15. Y.Z. Yang, X.Y. Zhang, Q.Q. Zeng, J.H. Yao, M.G. Qian, Experimental study of Litsea cubeba on cerebral thrombosis. Med. J. Chin. PLA 10(3), 207-208 (1985)

16. X. Chen, Z.W. Hu, X.L. Tang, N. Shen, Effect of the essential oil of Litsea cubeba (Lour) pers. on experimental myocardial infarction in rabbits and myocardial necrosis induced by isoprenaline in rats. Acta Pharm. Sin. 18(5), 388-391 (1983)

17. F.L. Zhang, Effect of Litsea cubeba oil on experimental arrhythmia. Chin. Trad. Herbal Drugs. 10(6), 14 (1985)

18. X.J. Fang, Function and application of Litsea cubeba oil. Hunan For. Sci. Technol. 34(3), 82-84 (2007). https://doi.org/10.3969/j. issn.1003-5710.2007.03.032

19. China Merchants Industrial Research Institute, Analysis on the development status and competition pattern of global and Chinese fragrance industry in 2019. (China Competition Information, 2019), https://www.askci.com/news/chanye/20190423/14401 91145224.shtml. Accessed 12 Jan 2020
20. Zhengzhou Maixuelong Food Spice Co., Ltd., Litsea cubeba essential oil price. (Food BusinessWeb, 2020), https://www.21foo d.cn/product/detail2465115.html. Accessed 12 Jan 2020

21. K. Andersson, Mosquito repellency of essential oils derived from Lao plants. (ResearchGate, 2010), https://www.researchgate.net/ profile/Thomas_Jaenson/publication/267686210_Mosquito_Repel lency_of_Essential_Oils_Derived_from_Lao_Plants/links/54733 91e0cf24bc8ea19cfbe/Mosquito-Repellency-of-Essential-OilsDerived-from-Lao-Plants.pdf . Accessed 13 Jan 2020

22. F. Li, S. Yaru, H. Howard, O.S. Kevin, Chemical component and activity analysis of Litsea cubeba extracts obtained by different extraction methods. Sci. Silva Sin. 51(3), 124-131 (2015)

23. Y.P. Bao, Progress and status of research on China Litsea cubeba oil. Chem. Ind. For. Prod. 15(2), 73-77 (1995)

24. Y.F. Xie, Y.L. Liang, F.X. Wang, W.J. Xiong, Y. Xu, X.Z. Liu, Study on enzymatic extraction of Litsea cubeba oil. Food Res. Dev. 14, 57-59 (2013). https://doi.org/10.3969/j. issn.1005-6521.2013.14.016

25. F. Li, J.B. Wu, H.Y. Xu, Supercritical carbon dioxide extraction of oil from Litsea cubebaand the antioxidant activity test of the oil. J. Xuzhou Inst. Technol. (Nat. Sci. Ed.). 27(2), 16-20 (2012). https://doi.org/10.3969/j.issn.1674-358X.2012.02.004

26. H.J. Fu, Effect of microwave on chemical components of Litsea cubeba oil and its antimicrobial activity. Food Sci. 37(17), 65-69 (2016). https://doi.org/10.7506/spkx1002-6630-20161 7011

27. C.J. Chen, Y. Li, X. Li, Research progress on technology methods for extracting plant volatile oil. Food Res. Dev. 32(11), 151-156 (2011). https://doi.org/10.3969/j.issn.1005-6521.2011.11.043

28. F.P. He, C.Y. Lei, J.X. Fan, D.Y. Gong, Z.M. Kang, R. Liu, S.Q. Han, L.N. Luo, X.B. Wu, Y. Peng, F.G. Ming, Research process of extraction methods, components and functional characteristics in essential oil. Sci. Technol. Food Ind. 40(3), 307-320 (2019). https://doi.org/10.13386/j.issn1002-0306.2019.03.049

29. H.H. Du, H. Zhu, A.Y. Chen, Study on extracting Litsea cubeba oil by ultrasonic-assisted vacuum distillation. Shandong Agric. Sci. 50(2), 133-138 (2018). https://doi.org/10.14083/j.i ssn.1001-4942.2018.02.027

30. L.L. Zhang, Research progress of microwave extraction technology to extract natural products. Biol. Teach. 41(4), 2-5 (2016)

31. Y.N. Chen, J.M. Zhang, Research progress of microwave-assisted extraction. Appl. Chem. Ind. 39(2), 270-279 (2010). https://doi. org/10.3969/j.issn.1671-3206.2010.02.031

32. X.G. Liu, M.M. Chen, B.P. Xie, Extraction of citral from Litsea cubeba fruits and determination of citral. Fine Chem. 18(7), 398 400 (2001). https://doi.org/10.3321/j.issn:1003-5214.2001.07.010

33. N. Qiu, J. Qin, Effect of time on microwave-assisted extraction of essential oil from Litsea Cubeba. J. Chifeng Univ. (Nat. Sci. Ed.) 32(8), 39-40 (2016). https://doi.org/10.3969/j. issn.1673-260X.2016.08.014

34. T.T. Hien, N.P.T. Nhan, N.D. Trinh, T.T.H. Van, G.B. Long, Optimizing the pomelo oils extraction process by microwave-assisted hydro-distillation using soft computing approaches. Solid State Phenom. 279, 217-221 (2018). https://doi.org/10.4028/www.scien tific.net/SSP.279.217

35. S. Mollaei, F. Sedighi, B. Habibi, S. Hazrati, P. Asgharian, Extraction of essential oils of Ferulago angulata with microwave-assisted hydro-distillation. Ind. Crop. Prod. 137, 43-51 (2019). https://doi.org/10.1016/j.indcrop.2019.05.015

36. N. Jeyaratnam, A.H. Nour, R. Kanthasamy, A.H. Nour, A.R. Yuvaraj, J.O. Akindoyo, Essential oil from Cinnamomum cassia bark through hydrodistillation and advanced microwave assisted hydrodistillation. Ind. Crop. Prod. 92(15), 57-66 (2016). https:// doi.org/10.1016/j.indcrop.2016.07.049

37. N. Deng, C.T. Kuang, L.Z. Wang, Y.L. Han, Study on extraction, chemical components and kinetics of Litsea cubeba oil. 
China Food Addit. 9, 80-84 (2014). https://doi.org/10.3969/j. issn.1006-2513.2014.09.004

38. A. Franco-Vega, N. Ramírez-Corona, A. López-Malo, E. Palou, Studying microwave assisted extraction of Laurus nobilis essential oil: static and dynamic modeling. J. Food Eng. 247, 1-8 (2019). https://doi.org/10.1016/j.jfoodeng.2018.11.007

39. X.J. Wu, X.S. Xu, Effects of storage conditions on the yield of Hyssopus oil. Jiangsu Condiment Subsidiary Food 4, 32-34 (2017). https://doi.org/10.16782/j.cnki.32-1235/ts.2017.04.009

40. Y.L. Han, C.T. Kuang, X.Z. Li, S.T. Jiang, Y. Li, Comparative study of extraction of Litsea cubeba essential oil by different methods. J. Central South Univ. For. Technol. 33(11), 175-178 (2013). https://doi.org/10.3969/j.issn.1673-923X.2013.11.034

41. W.J. Chen, Study on the relationship between the external color change of Litsea cubeba fruit and its oil yield and oil quality. J. Henan For. Sci. Technol. 21(2), 33-34 (2001). https://doi. org/10.3969/j.issn.1003-2630.2001.02.013

42. H.F. Zhang, X.H. Yang, Y. Wang, Microwave assisted extraction of secondary metabolites from plants: current status and future directions. Trends Food Sci. Technol. 22(12), 672-688 (2011). https://doi.org/10.1016/j.tifs.2011.07.003
43. M.L. Soran, M. Stan, Ü. Niinemets, L. Copolovici, Influence of microwave frequency electromagnetic radiation on terpene emission and content in aromatic plants. J. Plant Physiol. 171(15), 1436-1443 (2014). https://doi.org/10.1016/j.jplph.2014.06.013

44. X.J. Wu, Microwave assisted supercritical $\mathrm{CO}_{2}$ extraction of peppermint oil. Jiangsu Condiment Subsidiary Food (2018). https:// doi.org/10.16782/j.cnki.32-1235/ts.2018.04.009

45. Z.Y. Gu, L. Yang, H. Chen, M.H. Ran, R.N. Yang, Analysis of essential oil in pericarp from 6 wild Listea cubeba populations in Hunan province. J. Chin. Cer. Oils Assoc. 34(4), 87-91 (2019). https://doi.org/10.3969/j.issn.1003-0174.2019.04.016

46. Y.L. Han, Sturdy on extraction, refining and physical modification of Listea cubeba essential oil. Central South University of Forestry and Technology (2013).

Publisher's Note Springer Nature remains neutral with regard to jurisdictional claims in published maps and institutional affiliations. 